\title{
The role of open radical nephrectomy in contemporary management of renal cell carcinoma
}

\author{
Arveen A. Kalapara ${ }^{1 \wedge}$, Mark Frydenberg $^{1,2}$ \\ ${ }^{1}$ Department of Surgery, Monash University, Melbourne, Australia; ${ }^{2}$ Cabrini Institute, Cabrini Health, Melbourne, Australia \\ Contributions: (I) Conception and design: All authors; (II) Administrative support: None; (III) Provision of study materials or patients: None; (IV) \\ Collection and assembly of data: None; (V) Data analysis and interpretation: None; (VI) Manuscript writing: All authors; (VII) Final approval of \\ manuscript: All authors. \\ Correspondence to: Arveen A. Kalapara. Department of Surgery, Monash University, Melbourne, Australia. Email: arveenkalapara@gmail.com.
}

\begin{abstract}
Radical nephrectomy $(\mathrm{RN})$ remains a cornerstone of the management of localised renal cell carcinoma (RCC). RN involves the en bloc removal of the kidney along with perinephric fat enclosed within Gerota's fascia. Key principles of open RN include appropriate incision for adequate exposure, dissection and visualisation of the renal hilum, and early ligation of the renal artery and subsequently renal vein. Regional lymph node dissection (LND) facilitates local staging but its therapeutic role remains controversial. LND is recommended in patients with high risk clinically localised disease, but its benefit in low risk node-negative and clinically node-positive patients is unclear. Concomitant adrenalectomy should be reserved for patients with large tumours with radiographic evidence of adrenal involvement. Despite a recent downtrend in utilisation of open $\mathrm{RN}$ due to nephron-sparing and minimally invasive alternatives, there remains a vital role for open RN in the management of RCC in three domains. Firstly, open RN is important to the management of large, complex tumours which would be at high risk of complications if treated with partial nephrectomy (PN). Secondly, open RN plays a crucial role in cytoreductive nephrectomy $(\mathrm{CN})$ for metastatic RCC, in which the laparoscopic approach achieves similar results but is associated with a high reoperation rate. Finally, open RN is the current standard of care in the management of inferior vena caval (IVC) tumour thrombus. Management of tumour thrombus requires a multidisciplinary approach and varies with cranial extent of thrombus. Higher level thrombus may require hepatic mobilisation and circulatory support, whilst the presence of bland thrombus may warrant post-operative filter insertion or ligation of the IVC.
\end{abstract}

Keywords: Renal cell carcinoma (RCC); open radical nephrectomy (open RN); tumour thrombectomy; lymphadenectomy

Submitted Nov 05, 2019. Accepted for publication Jun 09, 2020.

doi: $10.21037 /$ tau-19-327

View this article at: http://dx.doi.org/10.21037/tau-19-327

\section{Introduction}

Renal cell carcinoma (RCC) remains a significant component of the global burden of cancer, accounting for 403,000 new diagnoses and 175,000 deaths worldwide in 2018 (1). Radical nephrectomy (RN) has long been a cornerstone of the management of localised RCC. However, downward stage migration due to early and incidental detection $(2,3)$ has sparked concerns of overtreatment, leading to the introduction of active surveillance, minimally invasive and nephron-sparing approaches to renal surgery and a downtrend in utilisation of open RN (4-6).

Nevertheless, there remains a vital role for open $\mathrm{RN}$ in the management of RCC. We present the technique of open $\mathrm{RN}$, its potential variations and outcomes. We also discuss

$\wedge$ ORCID: 0000-0003-3003-2655. 

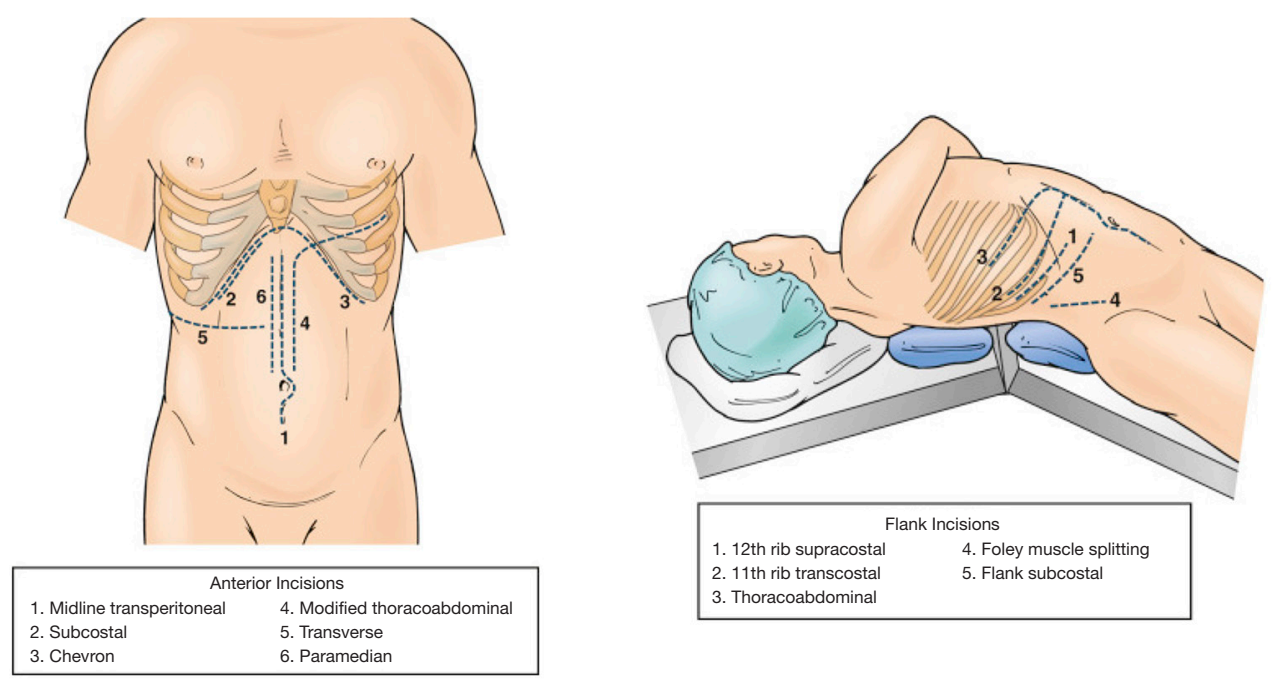

Figure 1 Incisions for anterior and flank approaches to radical nephrectomy. From ref (9) with permission.

the contemporary indications for open $\mathrm{RN}$, including the management of complex tumours, cytoreductive nephrectomy $(\mathrm{CN})$ and tumour thrombectomy.

\section{Technique}

First described by Frederic Foley in 1952, RN involves the en bloc removal of the kidney along with perinephric fat enclosed within Gerota's fascia (7), and has evolved to incorporate the removal of any regional lymphadenopathy (8). The approach to open $\mathrm{RN}$ can be classified as flank or anterior, and as either retroperitoneal, transperitoneal or thoraco-abdominal (9).

\section{Flank approach}

A flank approach to open $\mathrm{RN}$ provides good retroperitoneal exposure to the kidney. This involves positioning the patient in a lateral position on the side contralateral to the affected kidney, with table flexion centred superior to the patient's hip. The patient is secured in this position, with placement of an axillary roll along with padding around the knees to avoid neurovascular and pressure injuries.

A supracostal incision is made immediately superior to either the $11^{\text {th }}$ or $12^{\text {th }}$ rib, from the posterior axillary line to the linea semilunaris (Figure 1). Alternatively, an $11^{\text {th }}$ rib transcostal incision can be made, but requires subsequent division and removal of the rib. Underlying muscles are divided, including latissimus dorsi, external oblique and internal oblique, until the rib is reached.
Muscular attachments of intercostal muscles are divided off the superior border of the identified rib, and pleural attachments are peeled off the rib, to expose the intercostal space. Care must be taken to avoid inadvertent damage to the intercostal neurovascular bundle located below the rib above. The costovertebral ligament is then divided and a self-retaining retractor is used to displace the lower rib inferiorly and maximise exposure. The internal and external oblique muscle fasciae anterior to the tip of the $11^{\text {th }} / 12^{\text {th }}$ ribs are then divided under tension to allow further space. Once again, the intercostal neurovascular bundle must be identified deep to the internal oblique muscle prior to dissection through transversus abdominis and lumbodorsal fascia to enter the retroperitoneum.

The retroperitoneum and peri-renal space is developed with blunt dissection. The aorta or inferior vena cava (IVC) is then exposed by pushing the peritoneum anteriorly, and dissection is continued until the renal artery and vein are delineated. This vascular anatomy, and any variants, must be identified on pre-operative imaging including angiographic phase images. The position of the renal pelvis and proximal ureter are then identified. Vessel loops are placed around the renal artery and renal vein, and dissection of the hilum is continued to identify and ligate any branches of either main renal vessel. Any accessory arteries are also ligated at this point. Once the hilum is clear, the renal artery is first ligated twice and then divided. If the renal vein does not decompress following renal arterial ligation, this should raise concern of a missed accessory artery, which should subsequently be identified and ligated. The renal vein is 
then also double ligated and divided (9).

The lower pole of the kidney is mobilised, and the ureter is ligated and divided, facilitating inferior traction of the kidney and subsequent mobilisation of the upper pole. The adrenal gland is typically dissected off the upper renal pole in the absence of any pre-operative indication of tumour extension or metastasis. The kidney is freed, removed and prepared for pathological analysis. Following haemostasis, the table is partially unbroken to facilitate closure of the internal and external oblique muscles and skin in layers.

A retroperitoneal flank approach allows easy access to the kidney and renal hilum, and avoids involvement of the peritoneal cavity, reducing the risk of bowel injury and complications, particularly in patients with a history of abdominal surgery. However, both supracostal and transcostal flank approaches are associated with a risk of pleural injury, and also necessitate muscle division, resulting in increased pain and risk of incisional hernia. Less commonly, a transperitoneal thoracoabdominal incision can be made from a flank approach. This provides wider exposure for larger, upper pole masses and for renal vein or IVC tumour thrombectomy (9).

\section{Anterior approach}

Anterior approaches to open $\mathrm{RN}$ are transperitoneal and indicated when wide exposure is required, such as for large tumours or tumour thrombectomy. Potential incisions for this approach include subcostal, bilateral subcostal and midline (Figure 1). Following subcostal incision, abdominal muscles are divided as above and the peritoneum is entered. The posterolateral parietal peritoneum is incised along the line of Toldt and the ascending colon, or descending colon and spleen, is reflected medially in right and left nephrectomy, respectively. In a right $\mathrm{RN}$, the duodenum is then dissected and reflected medially to exposure the IVC and renal vein. Once Gerota's fascia is identified, it is incised anteromedially, the renal hilum is identified and the nephrectomy proceed as described above.

\section{Variations in technique}

\section{Lymph node dissection (LND)}

Pathological lymph node involvement is associated with poor cancer-specific survival (CSS) and overall survival (OS) of only $26-39 \%$ and $25-37 \%$ at 5 years following resection, respectively $(10,11)$. However, despite being a long-standing component of RN (8) and enduring in contemporary guideline recommendations (12), the therapeutic role of regional LND remains controversial.

LND for RCC involves removal of the precaval, retrocaval and paracaval nodes for right-sided tumours, or preaortic, retroaortic, paraaortic nodes for left-sided tumours, in addition to interaortocaval nodes from the crus of the diaphragm to the common iliac artery $(13,14)$. Although LND facilitates local staging and may guide the decision to offer adjuvant therapies, it remains unclear whether it offers a survival benefit in itself.

Routine LND in low risk clinically node-negative disease is not associated with survival benefit. Only one randomised trial has addressed LND in RCC, in which 732 patients with clinically localised disease were randomised to either RN with LND or RN only, as part of the European Organisation for Research and Treatment of Cancer (EORTC) trial 30881 (15). This revealed no difference in complications, or in progression-free or OS at 12 year follow up. However, this study comprised of a predominantly low-stage cohort with a $4 \%$ rate of unsuspected lymph node metastases, suggesting a large proportion could be managed with partial nephrectomy $(\mathrm{PN})$ in a contemporary setting. As such, the true impact of LND for larger, more aggressive tumours remains unknown (16).

LND is recommended in patients with high risk clinically localised disease (12), although observational studies report conflicting outcomes in this cohort. High risk features, including grade 3-4, stage pT3-T4, tumour necrosis and sarcomatoid appearance, are associated with increased risk of lymph node involvement (17). Population-based analyses of Surveillance, Epidemiology and End Results (SEER) data reveal an association between greater extent of LND/ positive node burden with lower OS among all patients (18), but suggest a benefit to CSS in stage pT3 tumours (19). This is supported by a large retrospective Italian study reporting an association between greater number of nodes removed and improved CSS in stage pT2-4 tumours, with a $3-19 \%$ increase in CSS with each additional lymph node removed (20).

The role of LND in clinically node-positive patients is less established. There is no clear benefit in patients with non-metastatic and high-risk non-metastatic disease (21). In two recent propensity score matched analyses of patients with non-metastatic RCC, LND was not associated with reduced risk of distant metastases, cancer-specific or overall mortality, among patients with $\mathrm{cN} 1$ disease on imaging, high risk disease but a clinical risk of less than $50 \%$ for $\mathrm{pN} 1$ 
disease, or with pN1 disease on pathology (22). Of note, the rate of $\mathrm{pN} 1$ disease was $6 \%$ in both cohorts. Other retrospective studies, however, suggest a durable CSS can be achieved in a subset of patients with isolated pN1M0 disease, ranging from $26-39 \%$ at 5 years and $21-31 \%$ at 10 years following nephrectomy with LND $(10,11,21,23)$. In the absence of firm evidence for a lack of benefit, international guidelines continue to recommend LND for staging and potential local control in patients with visible lymphadenopathy on pre-operative imaging (12).

Complications associated with LND include lymphocoele and bleeding from lumbar or large retroperitoneal vessels, and the incidence of these likely varies with the extent of dissection, extent of disease burden in the retroperitoneum and surgeon experience (24). Although these risks must be weighed against any potential oncological benefit in the decision to perform LND, rates of complications following nephrectomy with LND remain comparable with nephrectomy alone in both patients with non-metastatic and clinically node-positive disease $(15,25)$.

\section{Adrenalectomy}

Adrenal involvement of RCC can occur through haematogenous, lymphatic or direct spread, and risk factors include pT3 or greater tumour stage (26). Adrenalectomy at the time of open $\mathrm{RN}$ involves resection en bloc alongside the kidney within Gerota's fascia. Care must be taken to ligate and divide vascular connections to the adrenal gland cranially in a step-by-step manner, and to identify and ligate the right adrenal vein entering the IVC posterolaterally, or left adrenal vein entering the left renal vein (9).

Adrenalectomy should be reserved for patients with large tumours with evidence of adrenal involvement on pre-operative imaging (27). Although initially described as a component of $\mathrm{RN}$, routine ipsilateral adrenalectomy for otherwise localised or locally advanced disease has fallen out of favour for multiple reasons (12). Firstly, rates of ipsilateral adrenal involvement remain low. In a prospective series of 100 patients undergoing $\mathrm{RN}$ with ipsilateral adrenalectomy for localised disease, only $2 \%$ had RCC involvement of the adrenal gland on final pathology (28). Similarly, only 6\% of ipsilateral adrenalectomy specimens in a large North American series of patients undergoing nephrectomy contained RCC, including only $0.6 \%$ of those with clinically localised tumours (29). Only $11 \%$ metastasised from midlower poles, suggesting adrenalectomy is unnecessary lowstage, inferior tumours, whilst $60 \%$ were directly invading from an upper pole tumour. Even so, the presence of an upper pole tumour is not a significant predictor of disease recurrence warranting subsequent adrenalectomy, suggesting it is not required in the absence of radiological evidence of metastasis (30). Moreover, preoperative imaging is associated with a low false negative rate, and the perioperative risks of adrenalectomy must be considered in this context (31).

Finally, concomitant adrenalectomy does not offer a clear survival benefit. It is possible that any survival advantage seen in early series may not be applicable to contemporary practice due to downward stage migration and detection of tumours prior to adrenal involvement (32). Accordingly, recently published series reveal no significant benefit in 5and 10-year CSS for ipsilateral adrenalectomy compared with adrenal-sparing nephrectomy, particularly for pT1-2 tumours $(26,33,34)$.

\section{Outcomes of open RN}

\section{Oncological outcomes}

RCC offers excellent oncological outcomes, with a 5-year recurrence-free survival (RFS) of 86-91\%, CSS of 89-94\% and OS of $72-89 \%$ (35-37), and 10-year RFS of $87 \%$, CSS of $86 \%$ and OS of $58 \%$ (38) in pT1-2 tumours. Stage pT3 tumours are associated with a lower 5 -year CSS of $67 \%$ and OS of $62 \%$, which is to be anticipated given the relationship between increasing tumour size and poorer survival (39).

\section{Peri-operative morbidity}

RN has a 30 -day mortality of $0.5-1.8 \%$ (40-44). Perioperative mortality is associated with increasing tumour stage, ranging from $0.3 \%$ in T $1-2$ tumours to $1.3 \%$ in T3-4 tumours, and varies inversely with increasing surgeon and hospital operative volume $(41,43)$. Grade 3-4 Clavien-Dindo complications occur in $3-8 \%$ of patients undergoing RN (40,45). Stage T3-4 tumours and Charlson Comorbidity Index greater than 2 are both independently associated with greater risk of grade 3-4 Clavien complications (45). Rates of blood transfusion range between $10-11 \%(40,44)$. Splenic injury during is a rare but known complication of left RN and occurs in $0.8 \%$ of cases (46). Incisions required for open $\mathrm{RN}$ are significantly larger than those used in minimally-invasive alternatives, and may be associated with patient-important adverse outcomes including poor cosmesis or flank bulge secondary 
to intercostal nerve damage (47).

Inadvertent superior mesenteric artery injury (SMA) is an uncommon but life-threatening complication associated with RN. This is a particular risk during nephrectomy for large, left-sided tumours as the left renal vein passes in close proximity to the SMA at its origin from the aorta (48). This is often a result of poor exposure, made more difficult by large tumour size or bulky nodal disease, and can have catastrophic consequences resulting from bowel ischaemia. Although a rare complication, traumatic SMA injury is associated with a mortality rate over 50\% (49-51). As such, and open approach may be considered for large, left-sided tumours, with two surgeons present to ensure a safeguard against such errors.

\section{Contemporary issues in open RN}

\section{Indications}

Indications for $\mathrm{RN}$ include large tumour size and/or central location in the setting of a normal contralateral kidney, multiple ipsilateral renal lesions, venous tumour thrombus, and $\mathrm{CN}$ in the setting of local nodal or distant metastatic disease (9).

Since its introduction by Ralph Clayman in the 1990s, laparoscopic $\mathrm{RN}$ has seen widespread acceptance and utilisation (5,52). Laparoscopic RN offers excellent intermediate-long term oncological outcomes, with a 5 -year RFS of $92-95 \%$, CSS of $97-98 \%$ and OS of $81-88 \%$ (35-38,53).

However, open RN offers equivalent oncological control and survival benefit when compared with laparoscopic $\mathrm{RN}$ (54). In the absence of randomised evidence, several observational studies have revealed comparable survival at 5- and 10-years (35-37), and these outcomes remain similar regardless of cT1 or cT2 tumour stage $(37,38)$.

Laparoscopic RN is associated with favourable perioperative outcomes when compared to open RN. These include significantly shorter length of hospital stay, reduced blood loss but no reduced transfusion requirement, reduced post-operative analgesia requirements and earlier return to normal activity $(37,40,51,55,56)$. Although these perioperative benefits of laparoscopic RN persist in stage pT2 tumours $(37,57)$, endoscopic mobilisation remains technically challenging with increasing tumour size and complexity (58), suggesting open $\mathrm{RN}$ remains a relevant alternative, especially in the management of larger and more complex cases.

\section{Complex tumours}

An accurate assessment of tumour complexity is vital to preoperative decision making in the treatment of RCC. This inevitably involves the decision between $\mathrm{RN}$ and $\mathrm{PN}$ to balance oncological and peri-operative outcomes with the risk of renal impairment (59).

Relative indications for PN include tumour in a solitary kidney, bilateral renal masses and pre-existing renal impairment. International guidelines also recommend that clinically T1b tumours, between 4-7 cm in size, be managed with $\mathrm{PN}$ if feasible $(12,27)$. These indications must be considered through the lens of each patient's performance status, co-morbidities and risk of chronic kidney disease (CKD).

The only RCT comparing outcomes of RN and PN (EORTC 30904) found similar post-operative oncological outcomes and no difference in CSS, but lower OS in the PN group (60). This trial, however, was limited to tumours smaller than $5 \mathrm{~cm}$ in size and hampered by failure to accrual. Observational studies have reported conflicting evidence. A study of 1,600 patients with stage cT1 RCC revealed no significant difference in the risk of distant metastases, cancer-specific mortality or all-cause mortality (61), whilst others have suggested improved OS with $\mathrm{PN}$ via preservation of long-term renal function $(62,63)$. These studies are, however, at significant risk of selection bias, demonstrated in some cases by a paradoxical lowering of cancer-specific mortality with $\mathrm{PN}$ when compared to RN $(64,65)$.

However, nephron-sparing surgery does offer a clear advantage over $\mathrm{RN}$ in the preservation of renal function. In an analysis of the EORTC 30904 trial, moderate renal impairment [estimated glomerular filtration rate (eGFR) $<60$ ] was experienced by $86 \%$ of patients post-RN, significantly greater than $65 \%$ who underwent PN (66). Rates of more significant renal impairment (eGFR $<30$ and 15), however, were similar between techniques. Observational studies corroborate these findings, showing $\mathrm{RN}$ is associated with a two-fold risk of $10 \%$ or greater reduction in eGFR, and almost three-fold risk in eGFR decline to below 45 (61).

This is an important consideration given the association between even mild-moderate renal impairment and increased mortality $(67,68)$, and that surgically-induced CKD confers a greater risk of overall and non-renal cancer mortality in patients with pre-existing mild-moderate renal impairment of medical origin (69). 
Prediction models have been developed to decide between radical and nephron-sparing procedures. A recent, large retrospective study of 3,000 patients with over 31,000 eGFR measures demonstrated that age, pre-operative eGFR, comorbidities such as diabetes and hypertension, and tumour size interact in a complex dynamic to influence postoperative renal dysfunction (70). An important finding was the relationship between tumour size and renal impairment in RN and PN. Larger tumour size was associated with a small magnitude in eGFR reduction following $\mathrm{RN}$, perhaps as these tumours replace a significant proportion of renal parenchyma, leaving only a small functional proportion to be removed. Conversely, larger tumour size was associated with a significantly larger magnitude of reduction in eGFR following PN, potentially due to the removal of a larger proportion of normal renal parenchyma, or secondary to ischaemia during clamping of the renal artery (70-73). Increasing tumour complexity is also likely to influence both removal of additional parenchyma and ischaemia time.

This implies that the magnitude of functional benefit afforded by $\mathrm{PN}$ in smaller tumours may be limited in larger tumours. The limited benefit in preservation of renal function must be weighed against the increased risk of short-term morbidity associated with nephron-sparing surgery (74). Increasing RENAL (75) and PADUA (76) nephrometry scores indicate greater tumour complexity, and are associated with major post-operative complications following nephron-sparing surgery (74,77-79). Blood loss, rates of urine leak and reoperation are all greater in PN (80). PN may also be more technically challenging in larger and more complex tumours, with common reasons for conversion from $\mathrm{PN}$ to $\mathrm{RN}$ including hilar involvement and positive margins on frozen section (81). Considering these risks in the context of EORTC 30904 findings, patients with a normal contralateral kidney, normal renal function and minimal comorbid illnesses can be well served by RN especially in those larger tumours.

\section{CN}

$\mathrm{CN}$ remains at the crux of treating patients with metastatic RCC (12). Removal of the primary tumour is hypothesised to facilitate regression of remaining metastatic disease by allowing an immune-mediated response that was primed but sequestered prior to cytoreduction, or by removing the source of potential new metastases $(82,83)$. Early trials combining $\mathrm{CN}$ with interferon alpha demonstrated a significant survival benefit over interferon alpha alone
(84-86). However, since the shift from cytokines to more efficacious targeted therapies and immune checkpoint inhibitors, the need for $\mathrm{CN}$ has been questioned (87).

Retrospective studies of $\mathrm{CN}$ following targeted therapy reveal a benefit in OS favouring CN. Hazard ratios for OS following $\mathrm{CN}$ and tyrosine kinase inhibitor compared with targeted therapy alone range from $0.49-0.68$ (87-92). One study of 1,658 patients who underwent first-line targeted systemic therapy with or without $\mathrm{CN}$ showed that $\mathrm{CN}$ offered a survival benefit, notably in patients with survival greater than 12 months and less than 4 risk factors (88) as defined by the International Metastatic RCC Database Consortium (IMDC) or Memorial Sloan Kettering Cancer Center (MSKCC) criteria (93-96). Although these observational studies are hampered by selection bias, via inclusion of patients with good risk disease and inherently favourable performance status, this cohort may be the one to benefit most from $\mathrm{CN}$ (97).

A phase III randomised controlled trial (RCT) (Cancer du Rein Metastatique Nephrectomie et Antiangiogéniques: CARMENA) showed sunitinib alone was non-inferior to both sunitinib and CN (98), but included a high proportion of poor-risk patients with high metastatic burden who may not have benefited from surgery in the first instance. Another RCT (Immediate Surgery or Surgery After Sunitinib Malate in Treating Patients With Metastatic Kidney Cancer: SURTIME) revealed no significant difference in progression-free survival, but significantly improved OS (HR 0.57, 95\% CI: 0.34-0.95) with deferred CN compared to immediate CN (99). Again, this may be due to systemic therapy selecting out patients with rapid disease progression, in whom $\mathrm{CN}$ would be ineffective.

This body of evidence suggests that $\mathrm{CN}$ continues to have an important role in the management of well selected patients with favourable risk metastatic RCC.

\section{Complexity of CN and rationale for open vs. minimally invasive $\mathrm{CN}$}

Due to the complexity of many primary tumours and overall patient performance status in metastatic disease, $\mathrm{CN}$ is associated with high peri-operative morbidity. Peri-operative complication rates range from $12-31 \%$ (100-103) including 5-9\% Clavien-Dindo Grade 3 or greater (102-104). Pulmonary complications, thromboembolic events and acute renal failure are most common at 5\%,2-4\% and 3\%, respectively, following $\mathrm{CN}(102,103)$. Greater than 1,000 $\mathrm{mL}$ intraoperative blood loss has been reported in $15 \%$ of 


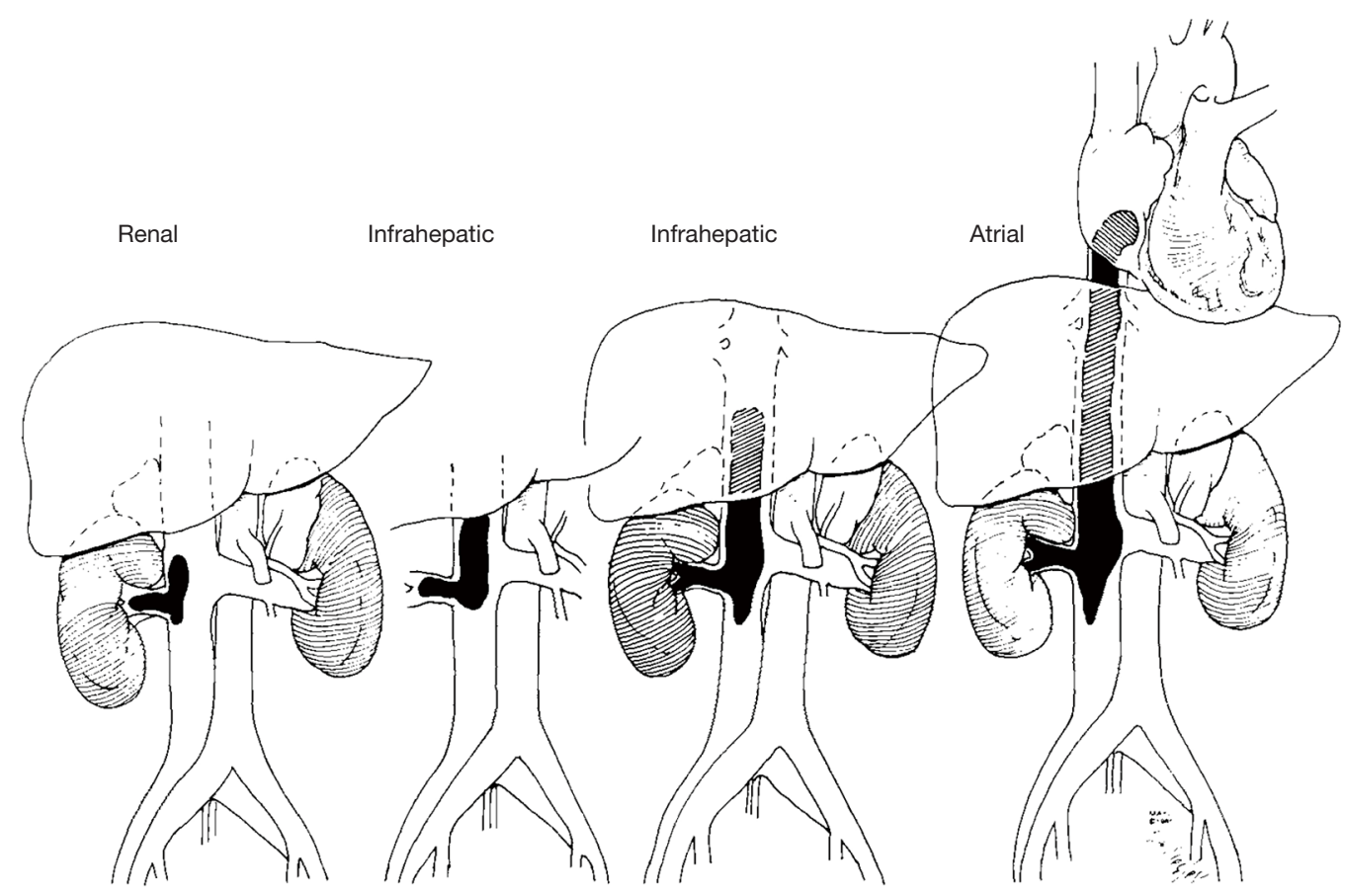

Figure 2 Level of venous tumour thrombus (from left to right: level I, II, III, IV). From ref (111) with permission. Used with permission of Mayo Foundation for Medical Education and Research, all rights reserved.

patients undergoing $\mathrm{CN}$, with tumour size over $10 \mathrm{~cm}, \mathrm{IVC}$ exploration for thrombus and number of metastatic sites all being independent predictors of this (104). Intraoperative splenic injury rate is higher than for non-CN at $1.4 \%$ (104). Rates of peri-operative mortality are also higher than $\mathrm{RN}$ for localised disease, at 1.5-5\% (100-104). Expectedly, this grows with increasing age to $4.8-21 \%$ in patients over the age of $75(101,105,106)$.

Given the complexity of these metastatic tumours, an open approach may best facilitate difficult dissection. Nonetheless, laparoscopic CN is also a feasible technique in metastatic RCC. Laparoscopic $\mathrm{CN}$ was associated with reduced blood loss (149-288 vs. 625-1,228 mL) and length of hospital stay (2.3-3.8 vs. 6-6.8 days) when compared with open $\mathrm{CN}$ (107-109). Open $\mathrm{CN}$ is also associated with increased rates of perioperative blood transfusion (104), however, overall complication rates remain equivalent between open and laparoscopic modalities (102). Notably, laparoscopic $\mathrm{CN}$ is associated with a shorter time to subsequent systemic therapy when compared with open $\mathrm{CN}$ $(102,107)$.

Nevertheless, it is important to note that in both of these aforementioned series, laparoscopy was not considered for very large tumours $(>14 \mathrm{~cm})$, and those managed with laparoscopy were significantly smaller than those resected via open technique $(107,108)$. Moreover, laparoscopic $\mathrm{CN}$ is associated with a relatively high rate of conversion to open of $5.3-14 \%(102,104)$, indicating a high level of complexity among these tumours. Considering these findings, open $\mathrm{CN}$ remains an important approach to renal surgery in metastatic disease.

\section{Tumour thrombectomy}

The presence of venous tumour thrombus warrants a modified approach to resection. Extension of tumour into the renal vein or IVC occurs in $4-10 \%$ of patients with RCC (110). Venous tumour thrombi (VTT) are stratified by extent of invasion (111) (Figure 2): level 0 thrombus is limited to the renal vein; level I thrombus extends into the IVC less than $2 \mathrm{~cm}$ above the renal vein; level II thrombus extends more than $2 \mathrm{~cm}$ above the renal vein but remains below the hepatic veins; level III thrombus extends into the IVC above the level of the hepatic veins but below the diaphragm, and level IV thrombus extends above the diaphragm (112). Venous tumour thrombus in 


\begin{tabular}{|c|c|c|c|}
\hline Preoperative Classification & $n=160$ & Tumor Thrombus Presentation & Post Thrombectomy IVC Management \\
\hline $\begin{array}{l}\text { Group A } \\
\text { IVC - No venous occlusion / } \\
\text { No associated distal or } \\
\text { bland thrombus }\end{array}$ & $120(75 \%)$ & & $\begin{array}{l}\text { Cavotomy } \\
\text { closure }\end{array}$ \\
\hline $\begin{array}{l}\text { Group B } \\
\text { IVC partially occluded / } \\
\text { Distal pelvic bland } \\
\text { thrombus }\end{array}$ & $4(2.5 \%)$ & & $\begin{array}{l}\text { Deploy } \\
\text { greenfield } \\
\text { filter }\end{array}$ \\
\hline $\begin{array}{l}\text { Group C } \\
\text { IVC total / partial occlusion } \\
\text { Associated bland thrombus/ }\end{array}$ & $23(14.4 \%)$ & & $\begin{array}{l}\text { IVC staple } \\
\text { ligation }\end{array}$ \\
\hline $\begin{array}{l}\text { Group D } \\
\text { IVC total occlusion } \\
\text { Associated bland thrombus }\end{array}$ & $13(8.1 \%)$ & & $\begin{array}{l}\text { IVC } \\
\text { segmental } \\
\text { resection }\end{array}$ \\
\hline
\end{tabular}

Figure 3 Mayo Clinic classification of bland thrombus. From ref (113) with permission. Used with permission of Mayo Foundation for Medical Education and Research, all rights reserved.

RCC typically consists of two parts; tumour thrombus and bland thrombus, the latter being any non-tumour material attached to the tumour thrombus (Figure 3) (113).

Venous tumour thrombus is a poor prognostic indicator, with a median survival of 5 months and 1-year CSS of $29 \%$ if managed conservatively (114). However, aggressive resection of the tumour and thrombus offers a marked improvement in median survival to 20 months (112). Despite evolving use of robotic-assisted resection of level 0 to II thrombus (115), the open approach remains vital in tumour thrombectomy.

\section{Technique}

Open RN with tumour thrombectomy varies significantly from the standard procedure described above. Firstly, variation in incision is usually required. A subcostal approach is usually taken, as the flank approach does not provide easy access to vena caval thrombus.

Key principles in controlling the tumour thrombus and minimising blood loss include clear exposure of the renal hilum, early ligation of the renal artery, and control of venous structures. The latter involves circumferential dissection of the IVC, and control of the IVC and its venous tributaries from above and below the thrombus, to facilitate occlusion in cases of significant venous tumour extension (112).

Extent of IVC manipulation required varies with the level of tumour thrombus extension (116). For lower level tumours, direct clamping temporarily above the thrombus whilst the IVC is opened and the tumour thrombus is extracted may be all that is necessary. Higher level tumours may require more extensive occlusion over longer durations. Accordingly, detailed assessment of preoperative imaging 
and identification of tumour thrombus level, any IVC occlusion, and its status as partial or complete, is critical for surgical planning and consideration of venous mobilisation and/or circulatory support for IVC occlusion (112).

\section{Level 0, I and II thrombi}

Level 0 and I VTT are managed similarly to RN with minimal manipulation of venous structures (116). Subcostal or thoracoabdominal incisions provide optimal exposure in these cases. Following incision, the bowel is mobilised medially to expose the retroperitoneum, and the kidney is mobilised around Gerota's fascia. The ureter and renal artery are identified and ligated. In right-sided tumours, ligation of the right renal artery in the interaortocaval region may be preferable in case of difficult exposure (112). In the case of Level 0 tumour thrombus, the renal vein is palpated to confirm thrombus presence and extension as identified on imaging. The renal vein is then controlled using a Satinsky vascular clamp and ligated distal to this point.

For level I tumour thrombi extending past the junction of the renal vein and IVC, ostial cavotomy with extraction of thrombus is indicated. If required, these thrombi can be reduced or "milked" back into the renal vein, with successive clamping. It is important to first identify, loop and tourniquet or clamp the infrarenal IVC, contralateral renal vein and suprarenal IVC, in that order, to minimise risk of thrombus embolisation. Reduction of the thrombus is followed by ligation of the renal vein or ostial cavotomy. If cavotomy is performed, the IVC should be inspected for any residual thrombus and be irrigated with heparinised saline, prior to closure with 3-0 or 4-0 polypropylene suture $(9,116)$.

Level II VTT require greater vascular control, including mobilisation of the entire IVC and contralateral renal vein, prior to cavotomy and thrombus extraction. Surrounding lumbar veins should be identified and ligated, prior to successive vascular clamping as described earlier. It is important to monitor for any significant haemodynamic deterioration on clamping prior to proceeding (116). Once the IVC has been controlled, cavotomy, thrombus extraction and closure are performed, as above.

\section{Level III and IV thrombi}

Resection of suprahepatic and supradiaphragmatic thrombi is challenging and requires a multi-disciplinary approach, with significant input from anaesthetists, vascular and cardiothoracic surgeons, and perfusionists. Larger thrombi extending into the intra- or supra-hepatic IVC warrant more extensive bilateral subcostal (Chevron) or thoracoabdominal incisions.

Liver mobilisation is required for intra-hepatic and supradiaphragmatic IVC thrombus. This involves progressive division of the ligamentum teres and falciform, right superior coronary, left triangular ligament, right inferior coronary and hepato-renal ligaments $(116,117)$. This allows the liver to be rotated medially, facilitating access to the suprahepatic IVC. The lesser omentum should be opened to allow access to the porta hepatis. The liver is dissected off the IVC until it is only attached via the major hepatic veins. At this point, the cranial extent of the thrombus is identified in the suprahepatic IVC. This may require inferior traction of the right atrium through the diaphragm (118). Temporarily occluding the porta hepatis using the Pringle manoeuvre can help decompress the liver prior to venous clamping. The infrarenal IVC, contralateral renal vein and suprahepatic IVC/right atrium are then clamped, in order, and the IVC is incised from diaphragm to renal vein to allow extraction of the thrombus (118). The opened IVC should also be inspected for any residual tumour, including orifices of the major hepatic veins. Importantly, intraoperative transoesophogeal echocardiography should be utilised during this process to monitor for tumour fracture and embolisation when manipulating extensive tumour thrombus.

Chronic IVC occlusion due to significant thrombus allows formation of collateral circulation. Venous return often relies on these collaterals in these patients, and care must be taken not to ligate these vessels particularly those on the contralateral side of the great vessels (113).

However, in some cases, resection of extensive IVC thrombus may require occlusion of the IVC for significant periods of time. Vascular bypass can be used to maintain end-organ perfusion, minimise blood loss and ensure a bloodless operative field. This can be achieved using cardiopulmonary bypass (CPB), with or without deep hypothermic cardiac arrest (DHCA), or veno-venous bypass (VVB) (119).

CPB involves cannulation of the superior or IVC for drainage and aorta for return (120), whilst VVB delivers blood from the infra-renal IVC or femoral vein to the right atrium, either directly or via the subclavian, internal jugular, axillary or cephalic veins, using an extracorporeal centrifugal pump (121). Small retrospective studies have suggested 
Table 1 Oncological outcomes of tumour thrombectomy by thrombus level $(112,126,127,131,132)$

\begin{tabular}{|c|c|c|c|c|}
\hline Thrombus level & Description & Proportion of all VTT (112) & 5-year CSS (112) & 10-year CSS (132) \\
\hline I & In IVC, within $2 \mathrm{~cm}$ above renal vein & $12 \%$ & $30-37 \%$ & $30 \%$ \\
\hline II & In IVC, $>2 \mathrm{~cm}$ above renal vein and below hepatic veins & $14 \%$ & $19-37 \%$ & $19 \%$ \\
\hline III & In IVC, above hepatic veins and below diaphragm & $5 \%$ & $19-49 \%$ & $19 \%$ \\
\hline
\end{tabular}

VTT, venous tumour thrombi; CSS, cancer-specific survival; IVC, inferior vena cava.

that VVB is associated with shorter operative and bypass times, but show no significant difference in peri-operative or survival outcomes (121). Evidence on the comparative effectiveness of these techniques remains scarce.

DHCA involves lowering core body temperature to allow closure of the CPB circuit, safely facilitating a bloodless field for thrombus resection and subsequent inspection and closure of the IVC $(122,123)$. Addition of DHCA may be safer than $\mathrm{CPB}$ alone, with a contemporary study revealing no significant improvement in blood loss, operative time or length of hospitalisation, but significantly lower perioperative mortality (8\% vs. 38\%) using CPB with DHCA than CPB alone (122). Nevertheless, CPB is associated with significant morbidity, with a $6.1 \%$ stroke risk $(119,124)$.

\section{Outcomes of tumour thrombectomy}

$\mathrm{RN}$ with tumour thrombectomy is associated with a 5 -year and 10 -year CSS of $36-41 \%$ and $24-38 \%$, respectively, among all patients $(112,125-128)$. Predictably, metastatic disease is associated with poorer prognosis, with 5 -year CSS ranging from 6-19\% in metastatic disease compared to $46-65 \%$ in non-metastatic disease. Other independent predictors of worse survival include greater tumour size, higher tumour Fuhrman grade, fat invasion and nodal metastases $(127,129)$. Presence of bland thrombus is an independent predictor of cancer-specific mortality (130).

Extent of tumour thrombus, however, does not clearly correlate with survival (129). Thrombus limited to the renal vein is associated with a significantly better survival than those at higher levels $(112,126,127)$ (Table 1). In a large retrospective series from the Mayo Clinic, patients with thrombus limited to the renal vein (level 0) had a significantly better 5 -year CSS of $49 \%$ than those with IVC invasion (level I-IV) at 31\% (112). However, there is conflicting evidence as to whether higher thrombus level within the IVC confers poorer CSS or OS, with most retrospective studies indicating no association, including between supra- and subdiaphragmatic thrombi (Table 1) $(112,125-127,129,132,133)$.

\section{Perioperative outcomes}

Any potential oncological benefit offered by tumour thrombectomy must be weighed against risk of perioperative morbidity. RN with tumour thrombectomy is associated with a perioperative mortality rate of $3-4 \%$, rising to $9.6 \%$ with IVC involvement, and $10.5 \%$ with thrombus extending above the hepatic veins $(129,134,135)$.

Rates of major complications are associated with increased thrombus level (112). Renal vein, IVC and supradiaphragmatic thrombi have $7-8 \%, 15-38 \%$ and $22-55 \%$ rates, respectively $(112,122,125,135)$. Tumour thrombectomy is also associated with a $1.5 \%$ incidence of intraoperative embolisation, with a subsequent $75 \%$ risk of mortality (136).

\section{Adjuncts to tumour thrombectomy}

Adjuncts to RN for venous tumour thrombus have been suggested depending on level of tumour extension. These include pre-operative renal artery embolization, IVC filter insertion and intra-operative cardio-pulmonary bypass.

Pre-operative embolisation of the renal artery has been suggested as a mechanism of aiding $\mathrm{RN}$, particularly in larger tumours. However, observational studies have shown an association between pre-operative embolization and greater blood loss, operative time, length of hospital stay and increased risk of peri-operative mortality $(137,138)$. It should be noted that these studies were of poor quality and at risk of selection bias, whereby larger tumours with greater venous invasion were treated with pre-operative 
embolization. Nevertheless, there is no clear evidence supporting this practice currently. An alternative to this may be early identification and ligation of the renal artery intraoperatively (139).

As thrombus fracture and embolisation is associated with high mortality rates, insertion of an IVC filter has been used in an attempt to mitigate this risk. However, this is no longer recommended pre-operatively following several reports of tumour disruption on placement, or subsequent tumour growth onto the filter (138). IVC filters may, however, have a role in the post-tumour thrombectomy setting to mitigate propagation of emboli from bland thrombus in the IVC or iliac veins.

\section{Bland thrombus}

Presence of bland thrombus, which usually occurs below the tumour thrombus in the common iliac veins, adjunct techniques are required to prevent embolisation and ensure clear surgical margins (Figure 3) (113). In the case of partial occlusion with distal bland thrombus, a Greenfield filter can be inserted at time of cavotomy to prevent upstream thrombus propagation (113), and is usually placed below the level of the renal vein. However, total occlusion of the IVC with bland thrombus warrants suture or staple ligation of the IVC between the bland and tumour thrombus. As mentioned above, lumbar and collateral veins provide venous return in patients with total occlusion, and ligation of several of these veins should be avoided (113). In some cases of total occlusion, the bland thrombus grows into the tumour thrombus. IVC resection may be required in these patients, with intraoperative frozen section to ensure negative margins (113).

\section{Conclusions}

Despite widespread uptake of minimally invasive and nephron-sparing surgery, open $\mathrm{RN}$ remains a safe and important approach to the management of RCC. Regional LND facilitates local staging but its therapeutic role remains controversial, whilst adrenalectomy should be only be performed for large tumours with radiographic evidence of adrenal involvement. Open $\mathrm{RN}$ is suitable for large and complex tumours not amenable to, or at risk of complications following, $\mathrm{PN}$ in patients with a normal contralateral kidney and minimal comorbid illnesses. Open $\mathrm{RN}$ may also be required to manage complex cytoreductive cases in which the laparoscopic approach is associated with high reoperation rates. Finally, open $\mathrm{RN}$ is crucial for tumour thrombectomy and often requires adjunct procedures to facilitate IVC access, occlusion, circulatory support and management of bland thrombus.

\section{Acknowledgments}

Funding: None.

\section{Footnote}

Provenance and Peer Review: This article was commissioned by the Guest Editor (Shomik Sengupta) for the series "Surgery for Urologic Cancers" published in Translational Andrology and Urology. The article has undergone external peer review.

Conflicts of Interest: Both authors have completed the ICMJE uniform disclosure form (available at http:// dx.doi.org/10.21037/tau-19-327). The series "Surgery for Urologic Cancers" was commissioned by the editorial office without any funding or sponsorship. The authors have no other conflicts of interest to declare.

Ethical Statement: The authors are accountable for all aspects of the work in ensuring that questions related to the accuracy or integrity of any part of the work are appropriately investigated and resolved.

Open Access Statement: This is an Open Access article distributed in accordance with the Creative Commons Attribution-NonCommercial-NoDerivs 4.0 International License (CC BY-NC-ND 4.0), which permits the noncommercial replication and distribution of the article with the strict proviso that no changes or edits are made and the original work is properly cited (including links to both the formal publication through the relevant DOI and the license). See: https://creativecommons.org/licenses/by-nc-nd/4.0/.

\section{References}

1. Bray F, Ferlay J, Soerjomataram I, et al. Global cancer statistics 2018: GLOBOCAN estimates of incidence and mortality worldwide for 36 cancers in 185 countries. CA Cancer J Clin 2018;68:394-424.

2. Patel HD, Gupta M, Joice GA, et al. Clinical Stage Migration and Survival for Renal Cell Carcinoma in the United States. Eur Urol Oncol 2019;2:343-8. 
3. Znaor A, Lortet-Tieulent J, Laversanne M, et al. International variations and trends in renal cell carcinoma incidence and mortality. Eur Urol 2015;67:519-30.

4. Jewett MA, Mattar K, Basiuk J, et al. Active surveillance of small renal masses: progression patterns of early stage kidney cancer. Eur Urol 2011;60:39-44.

5. Bianchi M, Becker A, Abdollah F, et al. Rates of open versus laparoscopic and partial versus radical nephrectomy for T1a renal cell carcinoma: a population-based evaluation. Int J Urol 2013;20:1064-71.

6. Poon SA, Silberstein JL, Chen LY, et al. Trends in partial and radical nephrectomy: an analysis of case logs from certifying urologists. J Urol 2013;190:464-9.

7. Foley FB, Mulvaney WP, Richardson EJ, et al. Radical nephrectomy for neoplasms. J Urol 1952;68:39-49.

8. Robson CJ. Radical nephrectomy for renal cell carcinoma. J Urol 1963;89:37-42.

9. Gregg JR, Scarpato KR. Chapter 8: Surgical Approaches for Open Renal Surgery, Including Open Radical Nephrectomy. In: Smith JA, Howards SS, Preminger GM, et al. editors. Hinman's Atlas of Urologic Surgery. 4th Edition ed. Philadelphia, PA: Elsevier, 2018:61-75.

10. Gershman B, Moreira DM, Thompson RH, et al. Renal Cell Carcinoma with Isolated Lymph Node Involvement: Long-term Natural History and Predictors of Oncologic Outcomes Following Surgical Resection. Eur Urol 2017;72:300-6.

11. Delacroix SE Jr, Chapin BF, Chen JJ, et al. Can a durable disease-free survival be achieved with surgical resection in patients with pathological node positive renal cell carcinoma? J Urol 2011;186:1236-41.

12. Ljungberg B, Albiges L, Bensalah K, et al. EAU Guidelines on Renal Cell Carcinoma 2019. European Association of Urology Guidelines. 2019 Edition. Arnhem, The Netherlands: European Association of Urology Guidelines Office, 2019.

13. Delacroix SE Jr, Chapin BF, Wood CG. The role of lymph node dissection in renal cell carcinoma. Urol Clin North Am 2011;38:419-28, vi.

14. Crispen PL, Breau RH, Allmer C, et al. Lymph node dissection at the time of radical nephrectomy for highrisk clear cell renal cell carcinoma: indications and recommendations for surgical templates. Eur Urol 2011;59:18-23.

15. Blom JH, van Poppel H, Marechal JM, et al. Radical nephrectomy with and without lymph-node dissection: final results of European Organization for Research and Treatment of Cancer (EORTC) randomized phase 3 trial
30881. Eur Urol 2009;5 5:28-34.

16. Studer UE, Birkhauser FD. Lymphadenectomy combined with radical nephrectomy: to do or not to do? Eur Urol 2009;55:35-7.

17. Blute ML, Leibovich BC, Cheville JC, et al. A protocol for performing extended lymph node dissection using primary tumor pathological features for patients treated with radical nephrectomy for clear cell renal cell carcinoma. J Urol 2004;172:465-9.

18. Joslyn SA, Sirintrapun SJ, Konety BR. Impact of lymphadenectomy and nodal burden in renal cell carcinoma: retrospective analysis of the National Surveillance, Epidemiology, and End Results database. Urology 2005;65:675-80.

19. Marchioni M, Bandini M, Pompe RS, et al. The impact of lymph node dissection and positive lymph nodes on cancer-specific mortality in contemporary pT2-3 nonmetastatic renal cell carcinoma treated with radical nephrectomy. BJU Int 2018;121:383-92.

20. Capitanio U, Suardi N, Matloob R, et al. Extent of lymph node dissection at nephrectomy affects cancerspecific survival and metastatic progression in specific subcategories of patients with renal cell carcinoma (RCC). BJU Int 2014;114:210-5.

21. Bhindi B, Wallis CJD, Boorjian SA, et al. The role of lymph node dissection in the management of renal cell carcinoma: a systematic review and meta-analysis. BJU Int 2018;121:684-98.

22. Gershman B, Thompson RH, Boorjian SA, et al. Radical Nephrectomy with or without Lymph Node Dissection for High Risk Nonmetastatic Renal Cell Carcinoma: A MultiInstitutional Analysis. J Urol 2018;199:1143-8.

23. Karakiewicz PI, Trinh QD, Bhojani N, et al. Renal cell carcinoma with nodal metastases in the absence of distant metastatic disease: prognostic indicators of disease-specific survival. Eur Urol 2007;51:1616-24.

24. Phillips CK, Taneja SS. The role of lymphadenectomy in the surgical management of renal cell carcinoma. Urol Oncol 2004;22:214-23; discussion 223-4.

25. Ristau BT, Manola J, Haas NB, et al. Retroperitoneal Lymphadenectomy for High Risk, Nonmetastatic Renal Cell Carcinoma: An Analysis of the ASSURE (ECOGACRIN 2805) Adjuvant Trial. J Urol 2018;199:53-9.

26. Siemer S, Lehmann J, Kamradt J, et al. Adrenal metastases in 1635 patients with renal cell carcinoma: outcome and indication for adrenalectomy. J Urol 2004;171:2155-9; discussion 2159.

27. Campbell S, Uzzo RG, Allaf ME, et al. Renal Mass 
and Localized Renal Cancer: AUA Guideline. J Urol 2017;198:520-9.

28. Kletscher BA, Qian J, Bostwick DG, et al. Prospective analysis of the incidence of ipsilateral adrenal metastasis in localized renal cell carcinoma. J Urol 1996;155:1844-6.

29. Tsui KH, Shvarts O, Barbaric Z, et al. Is adrenalectomy a necessary component of radical nephrectomy? UCLA experience with 511 radical nephrectomies. J Urol 2000;163:437-41.

30. Lane BR, Tiong HY, Campbell SC, et al. Management of the adrenal gland during partial nephrectomy. J Urol 2009;181:2430-6; discussion 2436-7.

31. Weight CJ, Mulders PF, Pantuck AJ, et al. The Role of Adrenalectomy in Renal Cancer. Eur Urol Focus 2016;1:251-7.

32. O'Malley RL, Godoy G, Kanofsky JA, et al. The necessity of adrenalectomy at the time of radical nephrectomy: a systematic review. J Urol 2009;181:2009-17.

33. Leibovitch I, Raviv G, Mor Y, et al. Reconsidering the necessity of ipsilateral adrenalectomy during radical nephrectomy for renal cell carcinoma. Urology 1995;46:316-20.

34. Kozak W, Holtl W, Pummer K, et al. Adrenalectomy--still a must in radical renal surgery? Br J Urol 1996;77:27-31.

35. Portis AJ, Yan Y, Landman J, et al. Long-term followup after laparoscopic radical nephrectomy. J Urol 2002;167:1257-62.

36. Chan DY, Cadeddu JA, Jarrett TW, et al. Laparoscopic radical nephrectomy: cancer control for renal cell carcinoma. J Urol 2001;166:2095-9; discussion 2099-100.

37. Hemal AK, Kumar A, Kumar R, et al. Laparoscopic versus open radical nephrectomy for large renal tumors: a longterm prospective comparison. J Urol 2007;177:862-6.

38. Permpongkosol S, Chan DY, Link RE, et al. Long-term survival analysis after laparoscopic radical nephrectomy. J Urol 2005; 174:1222-5.

39. Bhindi B, Thompson RH, Lohse CM, et al. The Probability of Aggressive Versus Indolent Histology Based on Renal Tumor Size: Implications for Surveillance and Treatment. Eur Urol 2018;74:489-97.

40. Henderson JM, Fowler S, Joyce A, et al. Perioperative outcomes of 6042 nephrectomies in 2012: surgeonreported results in the UK from the British Association of Urological Surgeons (BAUS) nephrectomy database. BJU Int 2015;115:121-6.

41. Cloutier V, Capitanio U, Zini L, et al. Thirty-day mortality after nephrectomy: clinical implications for informed consent. Eur Urol 2009;56:998-1003.
42. Mejean A, Vogt B, Quazza JE, et al. Mortality and morbidity after nephrectomy for renal cell carcinoma using a transperitoneal anterior subcostal incision. Eur Urol 1999;36:298-302.

43. Fernando A, Fowler S, Van Hemelrijck M, et al. Who is at risk of death from nephrectomy? An analysis of thirtyday mortality after 21380 nephrectomies in 3 years of the British Association of Urological Surgeons (BAUS) National Nephrectomy Audit. BJU Int 2017;120:358-64.

44. Carmignani G, Alchiede S, Corbu C, et al. Open Radical Nephrectomy: 35 Years of Experience at the "Luciano Giuliani" Urological Department of the University of Genoa. Eur Urol (Supp) 2006;5:593-9.

45. Hennus PM, Kroeze SG, Bosch JL, et al. Impact of comorbidity on complications after nephrectomy: use of the Clavien Classification of Surgical Complications. BJU Int 2012;110:682-7.

46. Wang JK, Tollefson MK, Kim SP, et al. Iatrogenic splenectomy during nephrectomy for renal tumors. Int J Urol 2013;20:896-902.

47. Chatterjee S, Nam R, Fleshner N, et al. Permanent flank bulge is a consequence of flank incision for radical nephrectomy in one half of patients. Urol Oncol 2004;22:36-9.

48. Moul JW, Foley JP, Wind GG, et al. Celiac axis and superior mesenteric artery injury associated with left radical nephrectomy for locally advanced renal cell carcinoma. J Urol 1991;146:1104-7; discussion 1107-8.

49. Asensio JA, Berne JD, Chahwan S, et al. Traumatic injury to the superior mesenteric artery. Am J Surg 1999;178:235-9.

50. Gill IS, Kavoussi LR, Clayman RV, et al. Complications of laparoscopic nephrectomy in 185 patients: a multiinstitutional review. J Urol 1995;154:479-83.

51. Dunn MD, Portis AJ, Shalhav AL, et al. Laparoscopic versus open radical nephrectomy: a 9-year experience. J Urol 2000;164:1153-9.

52. Clayman RV, Kavoussi LR, Soper NJ, et al. Laparoscopic nephrectomy: initial case report. J Urol 1991;146:278-82.

53. Ono Y, Kinukawa T, Hattori R, et al. The long-term outcome of laparoscopic radical nephrectomy for small renal cell carcinoma. J Urol 2001;165:1867-70.

54. MacLennan S, Imamura M, Lapitan MC, et al. Systematic review of oncological outcomes following surgical management of localised renal cancer. Eur Urol 2012;61:972-93.

55. Gratzke C, Seitz M, Bayrle F, et al. Quality of life and perioperative outcomes after retroperitoneoscopic radical 
nephrectomy $(\mathrm{RN})$, open $\mathrm{RN}$ and nephron-sparing surgery in patients with renal cell carcinoma. BJU Int 2009;104:470-5.

56. MacLennan S, Imamura M, Lapitan MC, et al. Systematic review of perioperative and quality-of-life outcomes following surgical management of localised renal cancer. Eur Urol 2012;62:1097-117.

57. Dillenburg W, Poulakis V, Skriapas K, et al.

Retroperitoneoscopic versus open surgical radical nephrectomy for large renal cell carcinoma in clinical stage cT2 or cT3a: quality of life, pain and reconvalescence. Eur Urol 2006;49:314-22; discussion 322-3.

58. Steinberg AP, Finelli A, Desai MM, et al. Laparoscopic radical nephrectomy for large (greater than $7 \mathrm{~cm}, \mathrm{~T} 2$ ) renal tumors. J Urol 2004;172:2172-6.

59. Smaldone MC, Churukanti G, Simhan J, et al. Clinical characteristics associated with treatment type for localized renal tumors: implications for practice pattern assessment. Urology 2013;81:269-75.

60. Van Poppel H, Da Pozzo L, Albrecht W, et al. A prospective, randomised EORTC intergroup phase 3 study comparing the oncologic outcome of elective nephronsparing surgery and radical nephrectomy for low-stage renal cell carcinoma. Eur Urol 2011;59:543-52.

61. Gershman B, Thompson RH, Boorjian SA, et al. Radical Versus Partial Nephrectomy for cT1 Renal Cell Carcinoma. Eur Urol 2018;74:825-32.

62. Capitanio U, Terrone C, Antonelli A, et al. Nephronsparing techniques independently decrease the risk of cardiovascular events relative to radical nephrectomy in patients with a T1a-T1b renal mass and normal preoperative renal function. Eur Urol 2015;67:683-9.

63. Weight CJ, Lieser G, Larson BT, et al. Partial nephrectomy is associated with improved overall survival compared to radical nephrectomy in patients with unanticipated benign renal tumours. Eur Urol 2010;58:293-8.

64. Shuch B, Hanley J, Lai J, et al. Overall survival advantage with partial nephrectomy: a bias of observational data? Cancer 2013;119:2981-9.

65. Tomaszewski JJ, Kutikov A. Retrospective comparison of cardiovascular risk in preselected patients undergoing kidney cancer surgery: reflection of reality or simply what we want to hear? Eur Urol 2015;67:690-1.

66. Scosyrev E, Messing EM, Sylvester R, et al. Renal function after nephron-sparing surgery versus radical nephrectomy: results from EORTC randomized trial 30904. Eur Urol 2014;65:372-7.
67. Go AS, Chertow GM, Fan D, et al. Chronic kidney disease and the risks of death, cardiovascular events, and hospitalization. N Engl J Med 2004;351:1296-305.

68. Antonelli A, Minervini A, Sandri M, et al. Below Safety Limits, Every Unit of Glomerular Filtration Rate Counts: Assessing the Relationship Between Renal Function and Cancer-specific Mortality in Renal Cell Carcinoma. Eur Urol 2018;74:661-7.

69. Lane BR, Demirjian S, Derweesh IH, et al. Survival and Functional Stability in Chronic Kidney Disease Due to Surgical Removal of Nephrons: Importance of the New Baseline Glomerular Filtration Rate. Eur Urol 2015;68:996-1003.

70. Bhindi B, Lohse CM, Schulte PJ, et al. Predicting Renal Function Outcomes After Partial and Radical Nephrectomy. Eur Urol 2019;75:766-72.

71. Thompson RH, Lane BR, Lohse CM, et al. Every minute counts when the renal hilum is clamped during partial nephrectomy. Eur Urol 2010;58:340-5.

72. Thompson RH, Lane BR, Lohse CM, et al. Renal function after partial nephrectomy: effect of warm ischemia relative to quantity and quality of preserved kidney. Urology 2012;79:356-60.

73. Mir MC, Campbell RA, Sharma N, et al. Parenchymal volume preservation and ischemia during partial nephrectomy: functional and volumetric analysis. Urology 2013;82:263-8.

74. Simhan J, Smaldone MC, Tsai KJ, et al. Objective measures of renal mass anatomic complexity predict rates of major complications following partial nephrectomy. Eur Urol 2011;60:724-30.

75. Kutikov A, Uzzo RG. The R.E.N.A.L. nephrometry score: a comprehensive standardized system for quantitating renal tumor size, location and depth. J Urol 2009;182:844-53.

76. Ficarra V, Novara G, Secco S, et al. Preoperative aspects and dimensions used for an anatomical (PADUA) classification of renal tumours in patients who are candidates for nephron-sparing surgery. Eur Urol 2009;56:786-93.

77. Hew MN, Baseskioglu B, Barwari K, et al. Critical appraisal of the PADUA classification and assessment of the R.E.N.A.L. nephrometry score in patients undergoing partial nephrectomy. J Urol 2011;186:42-6.

78. Ficarra V, Bhayani S, Porter J, et al. Predictors of warm ischemia time and perioperative complications in a multicenter, international series of robot-assisted partial nephrectomy. Eur Urol 2012;61:395-402. 
79. Klatte T, Ficarra V, Gratzke C, et al. A Literature Review of Renal Surgical Anatomy and Surgical Strategies for Partial Nephrectomy. Eur Urol 2015;68:980-92.

80. Van Poppel H, Da Pozzo L, Albrecht W, et al. A prospective randomized EORTC intergroup phase 3 study comparing the complications of elective nephron-sparing surgery and radical nephrectomy for low-stage renal cell carcinoma. Eur Urol 2007;51:1606-15.

81. Kara Ö, Maurice MJ, Mouracade P, et al. When Partial Nephrectomy is Unsuccessful: Understanding the Reasons for Conversion from Robotic Partial to Radical Nephrectomy at a Tertiary Referral Center. J Urol 2017;198:30-5.

82. Patel HD, Karam JA, Allaf ME. Surgical Management of Advanced Kidney Cancer: The Role of Cytoreductive Nephrectomy and Lymphadenectomy. J Clin Oncol 2018:JCO2018790246.

83. Psutka SP, Chang SL, Cahn D, et al. Reassessing the Role of Cytoreductive Nephrectomy for Metastatic Renal Cell Carcinoma in 2019. Am Soc Clin Oncol Educ Book 2019;39:276-83.

84. Flanigan RC, Salmon SE, Blumenstein BA, et al. Nephrectomy followed by interferon alfa-2b compared with interferon alfa-2b alone for metastatic renal-cell cancer. N Engl J Med 2001;345:1655-9.

85. Mickisch GH, Garin A, van Poppel H, et al. Radical nephrectomy plus interferon-alfa-based immunotherapy compared with interferon alfa alone in metastatic renal-cell carcinoma: a randomised trial. Lancet 2001;358:966-70.

86. Flanigan RC, Mickisch G, Sylvester R, et al. Cytoreductive nephrectomy in patients with metastatic renal cancer: a combined analysis. J Urol 2004;171:1071-6.

87. Bhindi B, Abel EJ, Albiges L, et al. Systematic Review of the Role of Cytoreductive Nephrectomy in the Targeted Therapy Era and Beyond: An Individualized Approach to Metastatic Renal Cell Carcinoma. Eur Urol 2019;75:111-28.

88. Heng DY, Wells JC, Rini BI, et al. Cytoreductive nephrectomy in patients with synchronous metastases from renal cell carcinoma: results from the International Metastatic Renal Cell Carcinoma Database Consortium. Eur Urol 2014;66:704-10.

89. Klatte T, Fife K, Welsh SJ, et al. Prognostic effect of cytoreductive nephrectomy in synchronous metastatic renal cell carcinoma: a comparative study using inverse probability of treatment weighting. World J Urol 2018;36:417-25.

90. Choueiri TK, Xie W, Kollmannsberger C, et al. The impact of cytoreductive nephrectomy on survival of patients with metastatic renal cell carcinoma receiving vascular endothelial growth factor targeted therapy. J Urol 2011;185:60-6.

91. Hanna N, Sun M, Meyer CP, et al. Survival Analyses of Patients With Metastatic Renal Cancer Treated With Targeted Therapy With or Without Cytoreductive Nephrectomy: A National Cancer Data Base Study. J Clin Oncol 2016;34:3267-75.

92. Patel MI, Beattie K, Bang A, et al. Cytoreductive nephrectomy for metastatic renal cell carcinoma: inequities in access exist despite improved survival. Cancer Med 2017;6:2188-93.

93. Mekhail TM, Abou-Jawde RM, Boumerhi G, et al. Validation and extension of the Memorial Sloan-Kettering prognostic factors model for survival in patients with previously untreated metastatic renal cell carcinoma. J Clin Oncol 2005;23:832-41.

94. Motzer RJ, Mazumdar M, Bacik J, et al. Survival and prognostic stratification of 670 patients with advanced renal cell carcinoma. J Clin Oncol 1999;17:2530-40.

95. Heng DY, Xie W, Regan MM, et al. Prognostic factors for overall survival in patients with metastatic renal cell carcinoma treated with vascular endothelial growth factortargeted agents: results from a large, multicenter study. J Clin Oncol 2009;27:5794-9.

96. Heng DY, Xie W, Regan MM, et al. External validation and comparison with other models of the International Metastatic Renal-Cell Carcinoma Database Consortium prognostic model: a population-based study. Lancet Oncol 2013;14:141-8.

97. Culp SH, Tannir NM, Abel EJ, et al. Can we better select patients with metastatic renal cell carcinoma for cytoreductive nephrectomy? Cancer 2010;116:3378-88.

98. Méjean A, Ravaud A, Thezenas S, et al. Sunitinib Alone or after Nephrectomy in Metastatic Renal-Cell Carcinoma. N Engl J Med 2018;379:417-27.

99. Bex A, Mulders P, Jewett M, et al. Comparison of Immediate vs. Deferred Cytoreductive Nephrectomy in Patients With Synchronous Metastatic Renal Cell Carcinoma Receiving Sunitinib: The SURTIME Randomized Clinical Trial. JAMA Oncol 2019;5:164-70.

100.Abdollah F, Sun M, Thuret R, et al. Mortality and morbidity after cytoreductive nephrectomy for metastatic renal cell carcinoma: a population-based study. Ann Surg Oncol 2011;18:2988-96.

101.Trinh QD, Bianchi M, Hansen J, et al. In-hospital mortality and failure to rescue after cytoreductive 
nephrectomy. Eur Urol 2013;63:1107-14.

102. Gershman B, Moreira DM, Boorjian SA, et al. Comprehensive Characterization of the Perioperative Morbidity of Cytoreductive Nephrectomy. Eur Urol 2016;69:84-91.

103. Silberstein JL, Adamy A, Maschino AC, et al. Systematic classification and prediction of complications after nephrectomy in patients with metastatic renal cell carcinoma (RCC). BJU Int 2012;110:1276-82.

104.Jackson BL, Fowler S, Williams ST, et al. Perioperative outcomes of cytoreductive nephrectomy in the UK in 2012. BJU Int 2015;116:905-10.

105. Sun M, Abdollah F, Schmitges J, et al. Cytoreductive nephrectomy in the elderly: a population-based cohort from the USA. BJU Int 2012;109:1807-12.

106.Kader AK, Tamboli P, Luongo T, et al. Cytoreductive nephrectomy in the elderly patient: the M. D. Anderson Cancer Center experience. J Urol 2007;177:855-60; discussion 860-1.

107. Rabets JC, Kaouk J, Fergany A, et al. Laparoscopic versus open cytoreductive nephrectomy for metastatic renal cell carcinoma. Urology 2004;64:930-4.

108. Matin SF, Madsen LT, Wood CG. Laparoscopic cytoreductive nephrectomy: the M. D. Anderson Cancer Center experience. Urology 2006;68:528-32.

109. Eisenberg MS, Meng MV, Master VA, et al. Laparoscopic versus open cytoreductive nephrectomy in advanced renalcell carcinoma. J Endourol 2006;20:504-8.

110. Boorjian SA, Sengupta S, Blute ML. Renal cell carcinoma: vena caval involvement. BJU Int 2007;99:1239-44.

111. Neves RJ, Zincke H. Surgical treatment of renal cancer with vena cava extension. Br J Urol 1987;59:390-5.

112. Blute ML, Leibovich BC, Lohse CM, et al. The Mayo Clinic experience with surgical management, complications and outcome for patients with renal cell carcinoma and venous tumour thrombus. BJU Int 2004;94:33-41.

113. Blute ML, Boorjian SA, Leibovich BC, et al. Results of inferior vena caval interruption by greenfield filter, ligation or resection during radical nephrectomy and tumor thrombectomy. J Urol 2007;178:440-5; discussion 444.

114. Reese AC, Whitson JM, Meng MV. Natural history of untreated renal cell carcinoma with venous tumor thrombus. Urol Oncol 2013;31:1305-9.

115.Aghazadeh MA, Goh AC. Robotic Left-sided Level II Caval Thrombectomy and Nephrectomy Using a Novel Supine, Single-dock Approach: Primary Description. Urology 2018;112:205-8.

116. Lawindy SM, Kurian T, Kim T, et al. Important surgical considerations in the management of renal cell carcinoma (RCC) with inferior vena cava (IVC) tumour thrombus. BJU Int 2012;110:926-39.

117. Ciancio G, Hawke C, Soloway M. The use of liver transplant techniques to aid in the surgical management of urological tumors. J Urol 2000;164:665-72.

118. Ciancio G, Gonzalez J, Shirodkar SP, et al. Liver transplantation techniques for the surgical management of renal cell carcinoma with tumor thrombus in the inferior vena cava: step-by-step description. Eur Urol 2011;59:401-6.

119.Pouliot F, Shuch B, Larochelle JC, et al. Contemporary management of renal tumors with venous tumor thrombus. J Urol 2010;184:833-41; quiz 1235.

120.Stewart JR, Carey JA, McDougal WS, et al. Cavoatrial tumor thrombectomy using cardipulmonary bypass without circulatory arrest. Ann Thorac Surg 1991;51:717-22.

121. Granberg CF, Boorjian SA, Schaff HV, et al. Surgical management, complications, and outcome of radical nephrectomy with inferior vena cava tumor thrombectomy facilitated by vascular bypass. Urology 2008;72:148-52 .

122. Shuch B, Crispen PL, Leibovich BC, et al. Cardiopulmonary bypass and renal cell carcinoma with level IV tumour thrombus: can deep hypothermic circulatory arrest limit perioperative mortality? BJU Int 2011;107:724-8.

123. Novick AC, Kaye MC, Cosgrove DM, et al. Experience with cardiopulmonary bypass and deep hypothermic circulatory arrest in the management of retroperitoneal tumors with large vena caval thrombi. Ann Surg 1990;212:472-6; discussion 476-7.

124. Svensson LG, Blackstone EH, Rajeswaran J, et al. Does the arterial cannulation site for circulatory arrest influence stroke risk? Ann Thorac Surg 2004;78:1274-84; discussion 1284.

125. Klatte T, Pantuck AJ, Riggs SB, et al. Prognostic factors for renal cell carcinoma with tumor thrombus extension. J Urol 2007;178:1189-95; discussion 1195.

126. Lambert EH, Pierorazio PM, Shabsigh A, et al. Prognostic risk stratification and clinical outcomes in patients undergoing surgical treatment for renal cell carcinoma with vascular tumor thrombus. Urology 2007;69:1054-8.

127. Martínez-Salamanca JI, Huang WC, Millan I, et al. Prognostic impact of the 2009 UICC/AJCC TNM staging system for renal cell carcinoma with venous extension. Eur Urol 2011;59:120-7.

128.Haferkamp A, Bastian PJ, Jakobi H, et al. Renal cell 
carcinoma with tumor thrombus extension into the vena cava: prospective long-term followup. J Urol 2007;177:1703-8.

129. Wagner B, Patard JJ, Mejean A, et al. Prognostic value of renal vein and inferior vena cava involvement in renal cell carcinoma. Eur Urol 2009;55:452-9.

130.Hutchinson R, Rew C, Chen G, et al. The Adverse Survival Implications of Bland Thrombus in Renal Cell Carcinoma With Venous Tumor Thrombus. Urology 2018;115:119-24.

131. Haddad AQ, Wood CG, Abel EJ, et al. Oncologic outcomes following surgical resection of renal cell carcinoma with inferior vena caval thrombus extending above the hepatic veins: a contemporary multicenter cohort. J Urol 2014;192:1050-6.

132. Moinzadeh A, Libertino JA. Prognostic significance of tumor thrombus level in patients with renal cell carcinoma and venous tumor thrombus extension. Is all $\mathrm{T} 3 \mathrm{~b}$ the same? J Urol 2004;171:598-601.

133. Al Otaibi M, Abou Youssif T, Alkhaldi A, et al. Renal cell carcinoma with inferior vena caval extention: impact of tumour extent on surgical outcome. BJU Int 2009; 104:1467-70.

134.Ali AS, Vasdev N, Shanmuganathan S, et al. The surgical management and prognosis of renal cell cancer with IVC

Cite this article as: Kalapara AA, Frydenberg M. The role of open radical nephrectomy in contemporary management of renal cell carcinoma. Transl Androl Urol 2020;9(6):3123-3139. doi: 10.21037/tau-19-327 tumor thrombus: 15-years of experience using a multispecialty approach at a single UK referral center. Urol Oncol 2013;31:1298-304.

135.Abel EJ, Thompson RH, Margulis V, et al. Perioperative outcomes following surgical resection of renal cell carcinoma with inferior vena cava thrombus extending above the hepatic veins: a contemporary multicenter experience. Eur Urol 2014;66:584-92.

136. Shuch B, Larochelle JC, Onyia T, et al. Intraoperative thrombus embolization during nephrectomy and tumor thrombectomy: critical analysis of the University of California-Los Angeles experience. J Urol 2009;181:492-8; discussion 498-9.

137. Subramanian VS, Stephenson AJ, Goldfarb DA, et al. Utility of preoperative renal artery embolization for management of renal tumors with inferior vena caval thrombi. Urology 2009; 74:154-9.

138. Lardas M, Stewart F, Scrimgeour D, et al. Systematic Review of Surgical Management of Nonmetastatic Renal Cell Carcinoma with Vena Caval Thrombus. Eur Urol 2016;70:265-80.

139. Gershman B, Leibovich BC. Assessing the Evidence for the Surgical Management of Renal Cell Carcinoma with Venous Tumor Thrombus: Room to Grow. Eur Urol 2016;70:281-2. 